\title{
CA (Formerly ISI) Recognition of NRR: Editorial
}

\author{
Emmanuel John M. Carranza ${ }^{1,2,3}$
}

In my first Editorial as Editor-in-Chief (EiC) of Natural Resources Research (NRR) (Carranza 2013), I said that it is my humble ambition to change the fact that NRR is not recognized yet by the Institute for Scientific Information, which has recently acquired a new name-Clarivate Analytics (CA). Now, after four years, it is my greatest pleasure to announce that NRR has been recognized by CA. Our journal (from its 2015 volume) will be listed in the Science Citation Index Expanded ${ }^{\mathrm{TM}}$ (also known as SciSearch ${ }^{\circledR}$ ), Journal Citation Reports ${ }^{\circledR}$ (JCR) Science Edition, and Current Contents ${ }^{\circledR} /$ Physical Chemical and Earth Sciences. This means that our first impact factors will be evaluated based on citations to papers published in 2015 and 2016, will be received in this year's JCR, and will be released sometime in mid 2018. In order to be accepted into the Science Citation Index, a journal must be evaluated against a number of objective criteria and standards (Garfield 1990). Therefore, the CA recognition is a significant acknowledgment of the high standard of our journal. It characterizes the culmination of the development of our journal since it was founded in 1992 by Richard McCammon.

I would like to thank every member of the editorial board for their respective contribution resulting in the CA recognition of NRR. At this point, I would like to introduce the following new members of our editorial board that were appointed during the last few months: Dr. Nandimandalam Janardhana Raju (School of Environmental Sci-

\footnotetext{
${ }^{1}$ Economic Geology Research Centre (EGRU), James Cook University, Townsville, QLD, Australia.

${ }^{2}$ Institute of Geosciences, State University of Campinas (UniCamp), Campinas, São Paulo, Brazil.

${ }^{3}$ To whom correspondence should be addressed; e-mail: ejmcarranza@gmail.com
}

ences, Jawaharlal Nehru University, India), who has expertise in hydrogeology and environmental geosciences; and editorial advisory board members Dr. Emil Attanasi (U.S. Geological Survey), who has expertise in energy resources, Dr. Xavier Emery (Department of Mining Engineering, University of Chile), who has expertise in geostatistics and mineral resources, and Dr. Mark J. Mihalasky (U.S. Geological Survey), who has expertise in mineral resources. Our current editorial board consists of internationally diverse members with expertises that that adequately cover the current aim and scope of NRR (i.e., hydrocarbon, geothermal, water, and mineral resources as well as geomathematics).

Traditionally, NRR is known for articles on the development of methods for mineral resource assessment and for mineral potential mapping. However, analyses of words in abstracts of papers published in NRR in the last four years (Fig. 1) show that, although most of the topics discussed vary from year to year, we have managed to attract good papers pertaining to water and energy resources. Our journal lacks articles on geothermal resources, and attracting papers on geothermal resources is challenging because we have to compete with good journals dedicated to geothermal resources, like Geothermics of Elsevier. Like many other journals, attracting submissions of papers has generally been a major challenge for NRR, mainly because authors prefer to submit their papers to JCR-indexed journals. Hopefully, with the CA recognition of our journal will help us overcome these challenges as no doubt this new development will make NRR more attractive to a broader authorship and so we can expect to see a raise in the number of submitted papers.

Peer reviewers contribute significantly to the standard of NRR. The main dilemma of journal editors is to find reviewers who have both the 


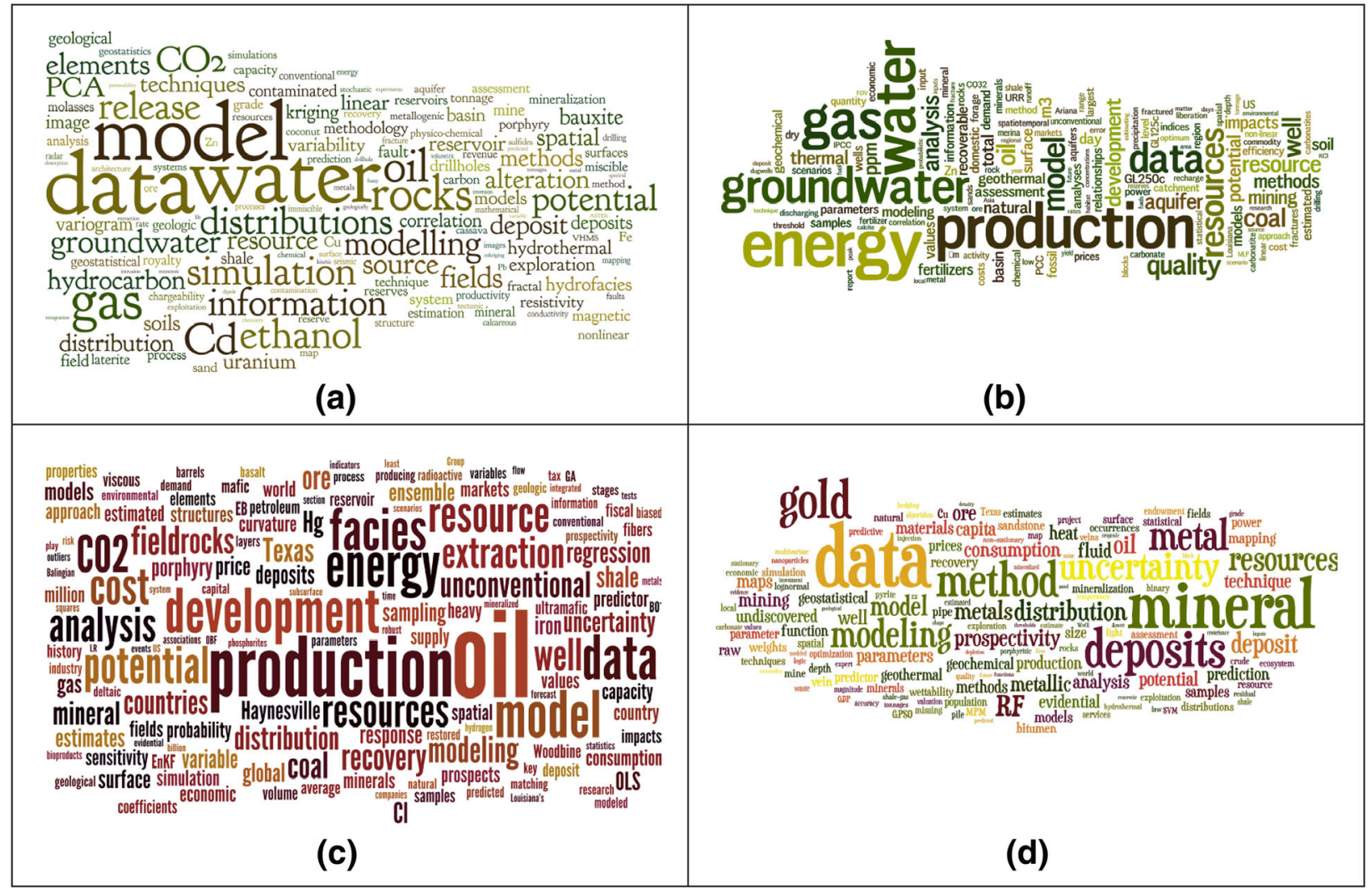

Figure 1. Clouds of words in the abstracts of NRR papers published in: (a) 2013, (b) 2014, (c) 2015, and (d) 2016. The word clouds were created using Wordle (http://www.wordle.net/).

expertise required and the time to make timely reviews of papers. Therefore, in every first annual issue of NRR since I took over as its EiC, we acknowledge individuals who have reviewed at least one paper in a preceding year. This is important because nowadays the efforts of peer reviewers are being recognized by research-related organizations like ORCID (Open Researcher and Contributor ID). I certainly am grateful to all reviewers for their contributions resulting in NRR's ISI recognition.

\section{REFERENCES}

Carranza, E. J. M. (2013). NRR, moving on: Editorial. Natural Resources Research, 22, 1-4.

Garfield, E. (1990). How ISI selects journals for coverage: quantitative and qualitative considerations. Current Contents, 13, $5-13$. 